\title{
Efficacy of interleukin-6 in combination with D-dimer in predicting early poor postoperative prognosis after acute stanford type a aortic dissection
}

Qingsong $\mathrm{Wu}^{1+}$, Jiahui $\mathrm{Li}^{1+}$, Liangwan Chen ${ }^{1 *}$ (D), Liang Liang Yan ${ }^{1}$, Zhihuang Qiu', Yue Shen ${ }^{1}$, Xianbiao Xie ${ }^{1}$ and Linfeng $\mathrm{Xie}^{2}$

\begin{abstract}
Background: We studied early poor postoperative prognosis in acute Stanford type A aortic dissection (ATAAD) patients and investigated the predictive effect of interleukin-6 (IL-6) combined with D-dimer in the early poor postoperative prognosis after ATAAD.
\end{abstract}

Methods: Data on 141 ATAAD patients, who underwent emergency surgery between January 2018 and December 2018 at our hospital, were studied. We analyzed early postoperative prognosis using two patient groups. Patients with good prognosis were included in group A and those with poor prognosis were in group B. Univariate logistic and multivariable logistic regression analysis were performed for poor early postoperative prognosis.

Results: Preoperative IL-6 level was lower (57.8 \pm 39.0 vs $211.0 \pm 153.7 \mathrm{pg} / \mathrm{mL}, p<0.001)$ and the D-dimer was also lower $(7.3 \pm 6.1$ vs. $16.7 \pm 5.8 \mu \mathrm{g} / \mathrm{mL}, p<0.001)$ in group A than in B. The cut-off points, determined by the ROC curve, were preoperative IL-6 $>108 \mathrm{pg} / \mathrm{mL}$ (area under the curve: AUC $=0.901$ ) and D-dimer $>14.0 \mu \mathrm{g} / \mathrm{mL}(\mathrm{AUC}=0.817$ ). Univariate logistic regression analysis showed that IL-6 > 108 pg/mL, D-dimer $>14.0 \mu \mathrm{g} / \mathrm{mL}$, prothrombin time $>15 \mathrm{~s}$, creatinine $>135 \mathrm{mmol} / \mathrm{mL}$, and operation time $>306 \mathrm{~min}$ for ATAAD appeared to be early postoperative risk factors of poor prognosis. Multivariable logistic regression analysis showed that IL-6 $>108 \mathrm{pg} / \mathrm{mL}$ and D-dimer $>14.0 \mathrm{\mu g} / \mathrm{mL}$ were early postoperative risk factors for poor prognosis after ATAAD, and the odds ratios (ORs) of IL- $6>108 \mathrm{pg} / \mathrm{mL}$ and D-dimer $>14.0 \mathrm{\mu g} / \mathrm{mL}$ were $24.937(6.837,90.931)$ and $18.757(5.094,69.075)$, respectively. When IL-6 was $>108 \mathrm{pg} / \mathrm{mL}$ (AUC $=0.901$ ), the sensitivity and specificity of predicting early postoperative prognosis after ATAAD were 79.4 and $89.7 \%$, respectively ( $95 \%$ confidence interval [Cl] 0.839 to 0.963 ). When D-dimer was $>14.0 \mathrm{~g} / \mathrm{mL}$ (AUC $=0.817$ ), the sensitivity and specificity were 82.4 and $84.1 \%$, respectively ( $95 \% \mathrm{Cl} 0.731$ to 0.903 ). When combined with D-dimer (AUC $=0.936)(95 \% \mathrm{Cl} 0.793$ to 0.979$)$, the AUC values were more predictive than those for the individual marker.

(Continued on next page)

\footnotetext{
* Correspondence: chengliangwan@tom.com

${ }^{\dagger}$ Qingsong Wu and Jiahui Li are contributed equally to this study and share first authorship.

'Department of Cardiac Surgery, Union Hospital, Fujian Medical University, Fuzhou, Fujian 350001, People's Republic of China

Full list of author information is available at the end of the article
} 
(Continued from previous page)

Conclusion: IL-6 $>108 \mathrm{pg} / \mathrm{mL}$ and D-dimer $>14.0 \mu \mathrm{g} / \mathrm{mL}$ is of high predictive value for the assessment of early poor postoperative prognosis after ATAAD. And IL-6 $>108 \mathrm{pg} / \mathrm{mL}$ in combination with D-dimer $>14.0 \mu \mathrm{g} / \mathrm{mL}$ is of higher predictive value.

Keywords: Acute Stanford a aortic dissection, Interleukin-6, D-dimer, Prognostic factor, Predictive value

\section{Introduction}

Acute Stanford type A aortic dissection (ATAAD) is a serious cardiovascular disease with a dangerous time course, rapid progression, and high mortality. Emergency surgery is the only effective treatment. Despite the continuous improvement of surgical techniques, surgical complications and mortality rates remain high [1-3].

Presently, no sensitive preoperative predictors for ATAAD patients with postoperative outcome assessments need. There is an urgent need for a variety of joint clinical predictors of the prognosis of patients with ATAAD to improve perioperative treatment and to help assess early ATAAD postoperative prognosis better. In addition, clinical predictors will optimize the treatment strategies, improve the early surgical treatment of ATAAD, reduce serious early postoperative complications, and reduce the incidence of poor early postoperative prognosis. It is also helpful for more accurate and precise consultations with patients and families before surgery, so that the family of the patient can fully understand the critical condition of the patient effectively; it is good for reducing some medical disputes.

Coagulation and inflammatory response mechanisms are important in the pathogenesis and prognosis of aortic dissection. Relevant studies have reported the sensitivity of D-dimer to the diagnosis of acute aortic dissection, and the elevation of D-dimer also affects the prognosis of acute aortic dissection. However, as a single indicator, the accuracy of D-dimer is insufficient, and its systematic evaluation in combination with other indicators may be required [4-6]. A large number of basic studies have shown that interleukin-6 (IL-6) is related to the pathology of aortic dissection. There have also been reports in clinical studies regarding effect of elevated IL- 6 on the occurrence of related complications after cardiovascular surgery $[3,7,8]$.

The combination of IL- 6 with D-dimer can provide valuable clinical predictive information for early poor postoperative prognosis after ATAAD and the combination has not been studied systematically. We therefore aimed to study the early poor postoperative prognosis in patients with ATAAD and to investigate the predictive effect of interleukin-6 (IL-6) combined with D-dimer in the early poor postoperative prognosis of ATAAD.

\section{Material and methods}

\section{Study population}

The preoperative IL-6 and D-dimer levels from $141 \mathrm{pa}-$ tients with emergency surgical treatment for ATAAD, from January to December 2018, were retrospectively collected. Postoperative complications were divided into two groups according to the Classification of Surgical Complications ${ }^{9}$ [9]: Those patients with good prognosis (Group $\mathrm{A}=$ Grade I, II, III) and those who had poor prognosis (group B = Grade IV, V) (Table 1).

We included patients in which ATAAD was confirmed by CT angiography (CTA) or magnetic resonance angiography (MRA) and emergency treatment was performed with aortic root treatment. This includes aortic sinus formation, bentall procedure, AVR, CABG, David procedure or Carbol procedure + ascending aorta replacement + hemiarch replacement + a self-adaptive triple-branched stent graft implantation or ascending aorta replacement + hemiarch replacement + a self-adaptive triple-branched stent graft implantation. We excluded patients who had been hospitalized for more than 48 $\mathrm{h}$ after onset, those with incomplete data, and patients with a history of malignant tumors or chronic single-organ dysfunction. This study was approved by the ethics committee of our hospital and conformed to the Declaration of Helsinki.

\section{Definitions}

A poor postoperative prognosis was defined a single organ dysfunction (including dialysis), multiorgan dysfunction

Table 1 Classification of Surgical complications

\section{Grade Defifinition}

Grade I Any deviation from the normal postoperative course without the need for pharmacological treatment or surgical, endoscopic, and radiological interventions

Allowed therapeutic regimens are: drugs as antiemetics, antipyretics, analgetics, diuretics, electrolytes, and physiotherapy. This grade also includes wound infections opened at the bedside

Grade II Requiring pharmacological treatment with drugs other than such allowed for grade I complications

Blood transfusions and total parenteral nutrition are also included

Grade III Requiring surgical, endoscopic or radiological intervention

Grade IIla Intervention not under general anesthesia

Grade IIIb Intervention under general anesthesia

Grade IV Life-threatening complication (including CNS complications) ${ }^{a}$ requiring IC/ICU management

Grade IVa Single organ dysfunction (including dialysis)

Grade IVb Multiorgan dysfunction

Grade $V$ Death of a patient

CNS central nervous system, IC intermediate care, ICU intensive care unit ${ }^{a}$ Brain hemorrhage, ischemic stroke, subarrachnoidal bleeding, but excluding transient ischemic attacks 
Table 2 Preoperative data on the two patient group

\begin{tabular}{|c|c|c|c|}
\hline Valuables & Group A $(\boldsymbol{n}=107)$ & Group B $(\boldsymbol{n}=34)$ & $\boldsymbol{P}$ value \\
\hline Male, n (\%) & $80(74.8)$ & $25(73.5)$ & 0.885 \\
\hline Age,n (year) & $51.6 \pm 10.6$ & $50.6 \pm 11.9$ & 0.660 \\
\hline $\mathrm{BMI}\left(\mathrm{Kg} / \mathrm{M}^{\wedge} 2\right)$ & $25.8 \pm 3.9$ & $25.6 \pm 4.2$ & 0.754 \\
\hline IL-6(pg/mL) & $57.8 \pm 39.0$ & $211.0 \pm 153.7$ & $<0.001$ \\
\hline D-dimer (ug/mL) & $7.3 \pm 6.1$ & $16.7 \pm 5.8$ & $<0.001$ \\
\hline Leukocyte(10^9/L) & $12.3 \pm 4.0$ & $12.8 \pm 4.7$ & 0.540 \\
\hline Neutrophile granulocyte(10^9/L) & $10.3 \pm 3.9$ & $10.8 \pm 4.3$ & 0.553 \\
\hline Leukomonocyte (10^9/L) & $1.1 \pm 0.5$ & $1.1 \pm 0.6$ & 0.924 \\
\hline PT (sec) & $15.7 \pm 13.7$ & $15.7 \pm 4.9$ & 0.982 \\
\hline Heamoglobin(g/L) & $129.5 \pm 23.6$ & $126.7 \pm 23.3$ & 0.553 \\
\hline Albumin(g/L) & $37.3 \pm 5.4$ & $35.4 \pm 4.6$ & 0.056 \\
\hline Troponin-I (ug/L) & $0.3 \pm 1.0$ & $1.9 \pm 6.5$ & 0.158 \\
\hline NT-ProBNP (pg/mL) & $704.1 \pm 1156.7$ & $1993.0 \pm 6129.2$ & 0.231 \\
\hline Serum creatinine (umol/L) & $93.1 \pm 42.4$ & $136.5 \pm 127.7$ & 0.060 \\
\hline Lactic acid (mmol/L) & $2.0 \pm 1.3$ & $1.6 \pm 1.3$ & 0.178 \\
\hline Alanine aminotransferase (IU/L) & $63.0 \pm 169.8$ & $166.5 \pm 473.0$ & 0.219 \\
\hline Aspartate aminotransferase (IU/L) & $69.0 \pm 226.2$ & $190.4 \pm 456.3$ & 0.145 \\
\hline $\mathrm{EF}(\%)$ & $63.8 \pm 7.0$ & $62.7 \pm 6.2$ & 0.371 \\
\hline Marfan Syndrome, n (\%) & $5(4.7)$ & $2(5.9 \%)$ & 0.865 \\
\hline Hypertension, n (\%) & $79(73.8)$ & $30(88.2)$ & 0.080 \\
\hline Diabetes, n (\%) & $9(8.4)$ & $1(2.9)$ & 0.485 \\
\hline Pericardial effusion (Medium or above), n (\%) & $5(4.7)$ & $4(11.8)$ & 0.715 \\
\hline MPS, n (\%) & $7(6.5)$ & $4(11.8)$ & 0.534 \\
\hline AR (Medium or above), n (\%) & $28(26.2)$ & $7(20.6)$ & 0.512 \\
\hline History of cardiac surgery, n (\%) & $8(7.5)$ & $4(11.8)$ & 0.669 \\
\hline
\end{tabular}

Continuous normally distributed variables were expressed as mean( \pm standard deviation) and not-normally distributed variables as medians (interquartile range)

Table 3 Surgical data on the two patient groups

\begin{tabular}{|c|c|c|c|}
\hline Valuables & Group A $(\boldsymbol{n}=107)$ & Group B $(\boldsymbol{n}=34)$ & $\boldsymbol{P}$ value \\
\hline \multicolumn{4}{|l|}{ Intraoperative time } \\
\hline Operative time (min) & $302.2 \pm 61.8$ & $317.1 \pm 57.8$ & 0.205 \\
\hline CPB time (min) & $148.6 \pm 38$ & $149.8 \pm 38.1$ & 0.874 \\
\hline Aortic Clamp time (min) & $49.2 \pm 18.9$ & $55.7 \pm 25.9$ & 0.187 \\
\hline SBP time (min) & $9.6 \pm 3.2$ & $10.1 \pm 4.3$ & 0.474 \\
\hline CA time (min) & $2.8 \pm 0.8$ & $3.2 \pm 1.3$ & 0.155 \\
\hline \multicolumn{4}{|c|}{ Aortic Root Concomitant procedure } \\
\hline Bentall,n(\%) & $24(22.4)$ & $6(17.6)$ & 0.724 \\
\hline AVR,n (\%) & $1(0.9)$ & $0(0.0)$ & 0.544 \\
\hline Cabrol,n(\%) & $0(0.0)$ & $1(2.9)$ & 0.544 \\
\hline$C A B G, n(\%)$ & $3(2.8)$ & $4(11.8)$ & 0.100 \\
\hline David,n(\%) & $1(0.9)$ & $0(0.0)$ & 0.544 \\
\hline Sinus forming,n (\%) & $47(43.9)$ & $10(29.4)$ & 0.193 \\
\hline
\end{tabular}




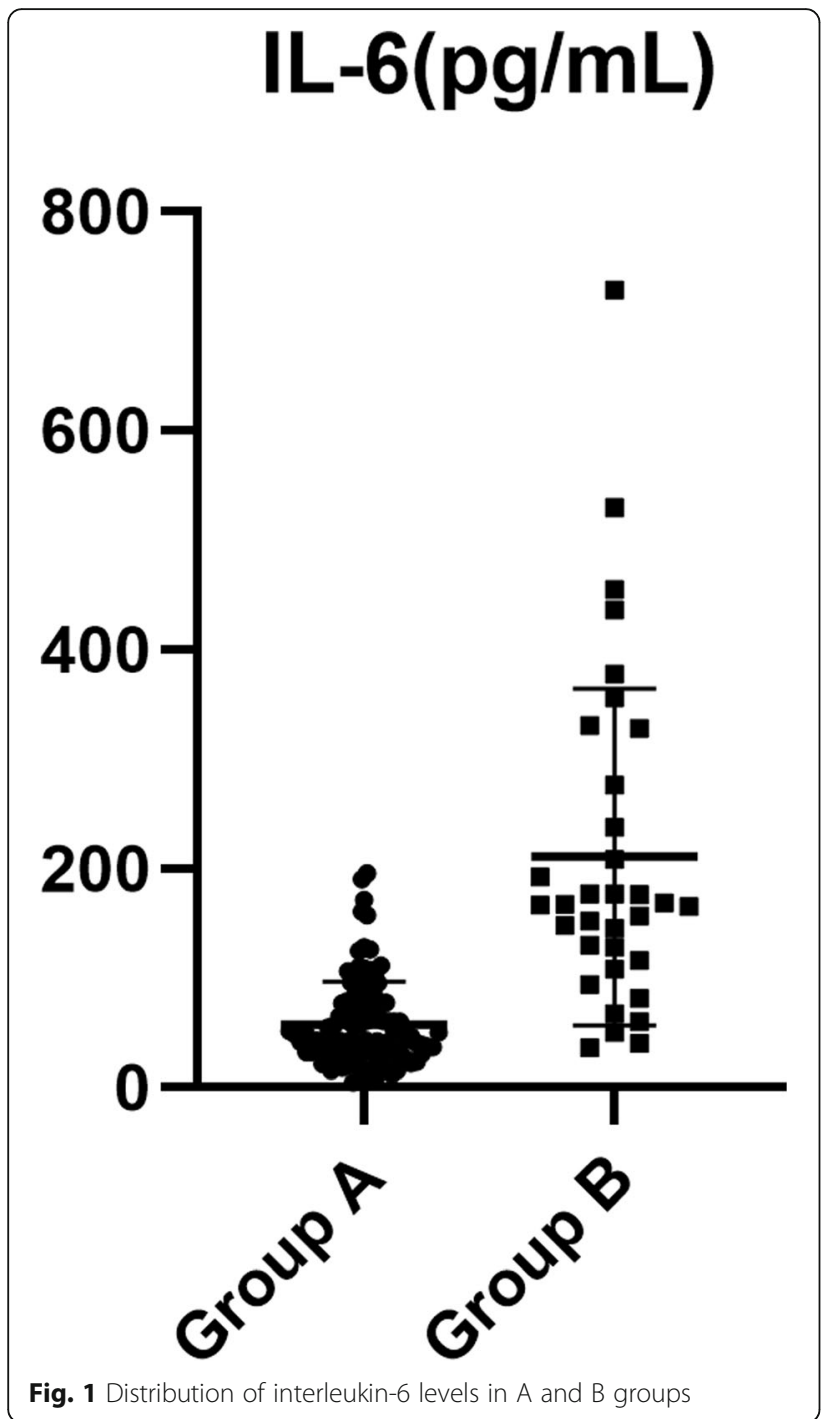

(MODS) and death. MODS was defined as acute and potentially reversible dysfunction of two or more organ systems due to a variety of different clinical factors [10]. Malperfusion syndrome (MPS) was presented as sequela of localized or systemic ischemia (because of compromised blood flow to a visceral vessel or a limb) at admission [11, 12].

An emergency operation was defined as urgent condition by the doctor after the assessment of the need for surgery in the shortest time, or if there was a life in danger. Aortic root treatment included aortic sinus formation, bentall procedure, AVR, CABG, David procedure, and Carbol procedure.

\section{Serum measurements}

All patients were admitted to the hospital (within $48 \mathrm{~h}$ after onset, without medication), and venous blood was extracted before surgery.

\section{D-dimer(ug/mL)}

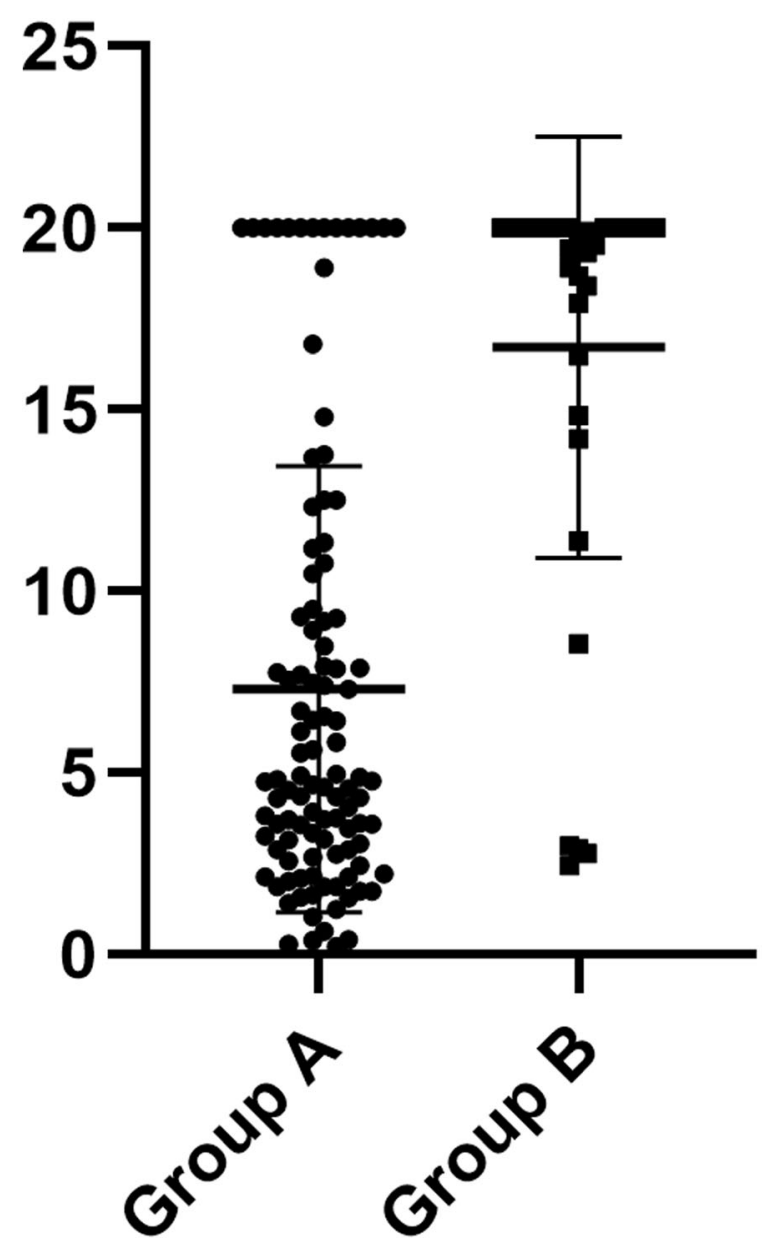

Fig. 2 Distribution of D-dimer levels in A and B groups

Operative treatment $[13,14]$

The details of the surgical procedure performed with aortic root treatment (includes aortic sinus formation, bentall procedure, AVR, CABG, David procedure orCarbol procedure) + ascending aorta replacement + Hemiarch Replacement + a self-adaptive triplebranched stent graft implantation have been described. All patients underwent total cardiopulmonary bypass.

The preoperative 25 indexes of all patients were observed and summarized. Preoperative indicators included age, gender, body mass index (BMI), IL-6, Ddimer, leukocyte, neutrophil granulocyte, lymphocyte, hemoglobin, albumin, prothrombin time (PT) and the NT-ProBNP, troponin I, serum creatinine, lactic acid, alanine aminotransferase, aspartate aminotransferase, preoperative ejection fraction (EF), Marfan syndrome, 
hypertension, diabetes, pericardial effusion (medium or above), organ perfusion, aortic regurgitation (AR) (moderate or above) and a history of cardiac surgery. Six intraoperative indicators were operative methods of the aortic root and operative data (operation, cardiopulmonary bypass (CPB), aortic clamp, selective cerebral perfusion (SBP),and circulatory arrest (CA) times) (Tables 2 and 3). Early postoperative prognosis, using the hierarchical classification based on Complications of Surgical Complications in two groups, was divided between Group A with good prognosis and Group B with poor prognosis.

Continuous variables were analyzed using MannWhitney $U$ test and presented by the mean \pm standard deviation, or mean (min, max), while categorical variables were tested by a chi-squared test or Fisher's exact test. According to receiver operating characteristics (ROC) curve, cut-off point was selected, and variables with a $p$-value $<0.10$ for a single factor were selected for logistic regression analysis of related risk factors in patients. $P$-values $<0.05$ were considered statistically significant. All data were statistically processed using the SPSS 19.0 statistical software package.

\section{Results}

In 141 patients with ATAAD cases, poor early postoperative prognosis was seen in 34 (24.1\%). Of these, renal failure involved 17 (12.1\%) patients, respiratory failure, $3(2.1 \%)$, liver failure, $1(1.4 \%)$, digestive system dysfunction in 1 $(0.7 \%)$, nervous system dysfunction $(0.7 \%)$, sepsis, $1(0.7 \%)$, and MODS $2(1.4 \%)$ cases. While 8 (5.7\%) patients died, there were 107 cases with good postoperative prognosis.

Preoperative IL-6 level was lower $(57.8 \pm 39.0$ vs. $211.0 \pm 153.7 \mathrm{pg} / \mathrm{mL}, P<0.001)$ and $\mathrm{D}$-dimer level was also lower $(7.3 \pm 6.1$ vs. $16.7 \pm 5.8 \mu \mathrm{g} / \mathrm{mL}, P<0.001)$ in group A than in group B. The cut-off points, determined by ROC curve, where preoperative IL- 6 was $>108 \mathrm{pg} / \mathrm{mL}$ (area under the curve: AUC $=0.901$ ) and D-dimer $>14.0$ $\mu \mathrm{g} / \mathrm{mL}(\mathrm{AUC}=0.817)$ (Tables 2 and 5, Figs. 1, 2, and 3).

Univariate analysis of poor prognosis showed that IL$6>108 \mathrm{pg} / \mathrm{mL}$, D-dimer $>14.0 \mu \mathrm{g} / \mathrm{mL}, \mathrm{PT}>15 \mathrm{~s}$, creatinine tend for greater than $135 \mathrm{~mL}$ and operation time $>$ 306 min were predictors of adverse postoperative prognostic risk factors (Table 3 and Fig. 4). Multiple factor analysis showed that IL-6 $>108 \mathrm{pg} / \mathrm{mL}$, D-dimer $>14.0$ $\mu \mathrm{g} / \mathrm{mL}$ were the independent risk factors of early poor

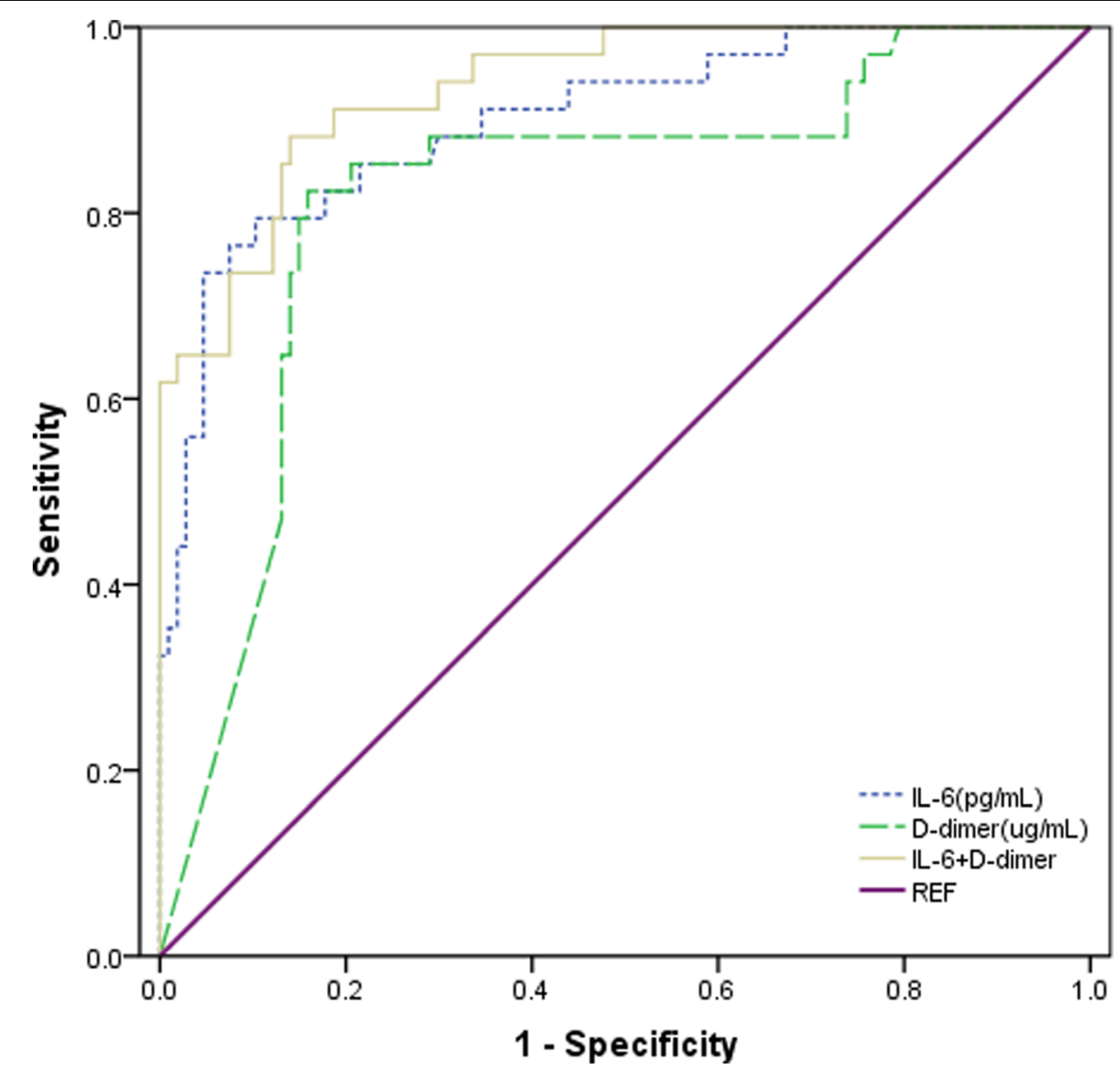

Fig. 3 Receiver-operating characteristic curve in the prediction of the independent risk factors of early poor postoperative prognosis after Acute Stanford type A aortic dissection 


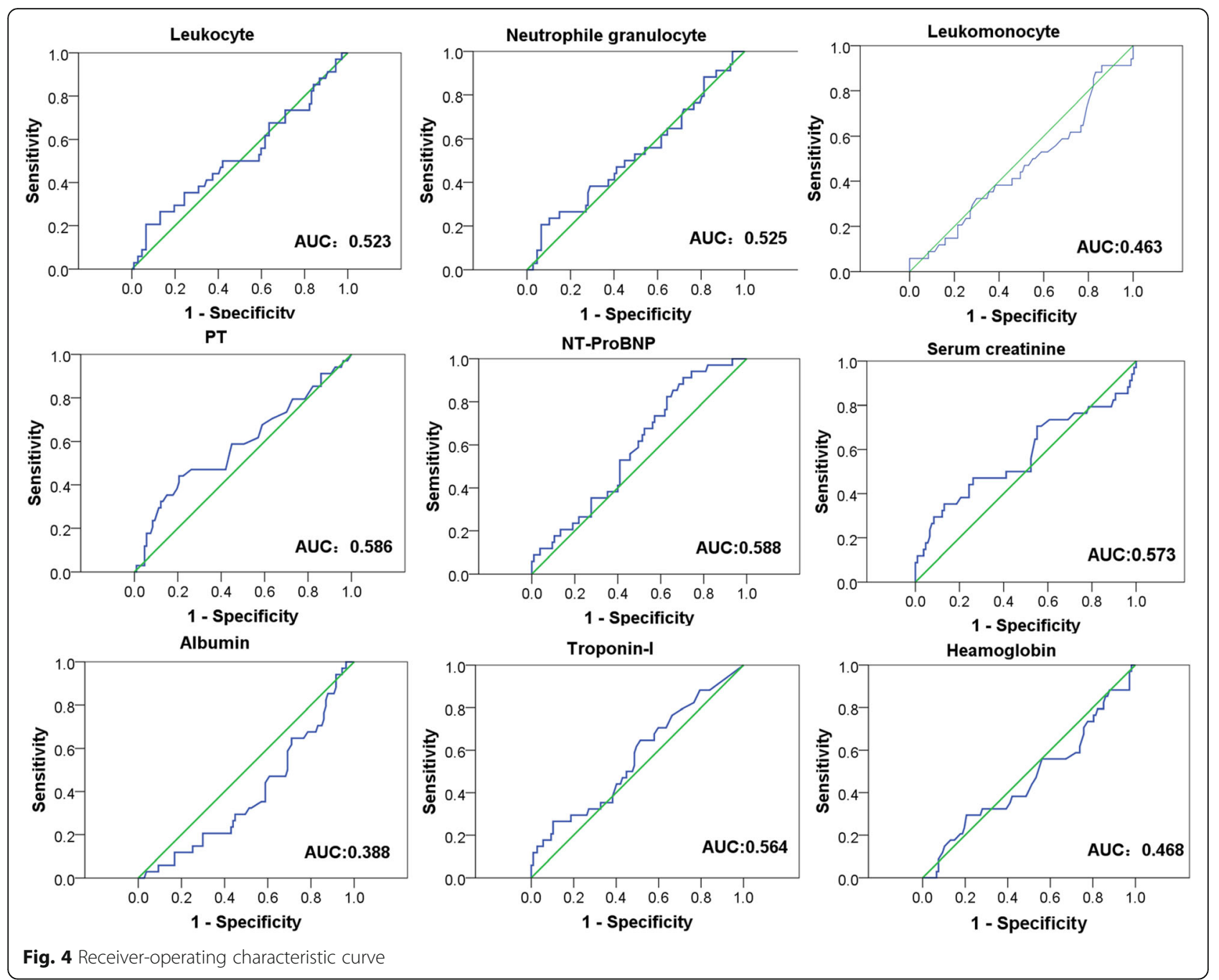

postoperative prognosis after ATAAD (Table 4). ORs of IL-6 $>108 \mathrm{pg} / \mathrm{mL}$ and D-dimer $>14.0 \mu \mathrm{g} / \mathrm{mL}$ were $24.937(6.837,90.931)$ and 18.757 (5.094, 69.075), respectively. The sensitivity and specificity of IL-6 $>108$ $\mathrm{pg} / \mathrm{mL}$ for early adverse prognosis after ATAAD were 91.2 and $89.7 \%$, respectively (95\% CI 0.839 to 0.963 ). The sensitivity and specificity of D-dimer $>14.0 \mu \mathrm{g} / \mathrm{mL}$ were 88.2 and $82.2 \%$, respectively (95\% CI 0.731 to 0.903) (Tables 4 and 5, Fig. 3).

When IL-6 was combined with D-dimer, the AUC reached 0.936 (95\% CI 0.793 to 0.979). The AUC values for the combined indicators were more predictive than with the individual marker alone (Fig. 3).

In summary, IL- 6 and D-dimer were strong predictors of early poor postoperative prognosis after ATAAD, and they were more accurate when used in combination.

\section{Discussion}

ATAAD is a fatal cardiovascular disease and poses a serious threat to human life and health [15]. Surgery is the treatment of choice, and without surgery, the mortality rate of ATAAD within $48 \mathrm{~h}$ is $50 \%$. However, the mortality rate remains high after surgery due to many postoperative complications [16]. Relevant studies have shown that most patients with ATAAD had increased IL-6 before surgery. Intercellular IL-6 is an inflammatory cytokine, which plays an important role in inflammation and immune response and is closely related to cardiovascular diseases [17]. A functional multipotent prototype cytokine also has an important role in host defense. When infection or tissue damage occurs, IL-6 is rapidly produced by monocytes and macrophages; and it helps remove infectious agents and restore damaged tissues by activating immunity, blood, and acute phase reactions [18]. It has been found that there is an elevation in the early stage of acute aortic dissection, but the predictive value of the clinical outcome of acute aortic dissection is still lacking [19]. D-dimer is a cross-linked fibrin degradation product, suggesting that aortic dissection has fibrinolytic activity, which can be detected in peripheral 
Table 4 Univariate and multivariate analyses for all patients who underwent surgery

\begin{tabular}{|c|c|c|c|c|c|c|}
\hline \multirow[t]{2}{*}{ Variable } & \multicolumn{3}{|c|}{ Univariate Model } & \multicolumn{3}{|c|}{ Multivariate Model } \\
\hline & $\overline{\mathrm{OR}}$ & $95 \% \mathrm{Cl}$ & $\overline{p \text {-value }}$ & $\overline{\mathrm{OR}}$ & $95 \% \mathrm{Cl}$ & $\overline{p \text {-value }}$ \\
\hline \multicolumn{7}{|c|}{ Age, years } \\
\hline$<60$ & REF & & & & & \\
\hline$\geq 60$ & 1.016 & $0.423-2.438$ & 0.885 & & & \\
\hline \multicolumn{7}{|c|}{ BMI, kg/m } \\
\hline$<25$ & REF & & & & & \\
\hline$\geq 25$ & 0.621 & $0.286-1.349$ & 0.228 & & & \\
\hline \multicolumn{7}{|l|}{ Sex } \\
\hline Female & REF & & & & & \\
\hline Male & 1.067 & $0.443-2.566$ & 0.885 & & & \\
\hline \multicolumn{7}{|c|}{$\mathrm{IL}-6(\mathrm{pg} / \mathrm{mL})$} \\
\hline$\leq 108$ & REF & & & REF & & \\
\hline$>108$ & 33.662 & 11.906-95.178 & $<0.001$ & 24.937 & $6.837-90.931$ & $<0.001$ \\
\hline \multicolumn{7}{|c|}{ D-dimer (ug/mL) } \\
\hline$\leq 14.0$ & REF & & & REF & & \\
\hline$>14.0$ & 24.706 & $8.884-68.705$ & $<0.001$ & 18.757 & $5.094-69.075$ & $<0.001$ \\
\hline \multicolumn{7}{|l|}{ PT (sec) } \\
\hline$\leq 15.0$ & REF & & & REF & & \\
\hline$>15.0$ & 2.667 & $1.12-6.346$ & 0.027 & 1.198 & $0.268-5.350$ & 0.813 \\
\hline \multicolumn{7}{|c|}{ Heamoglobin (10^9/L) } \\
\hline$\leq 10$ & REF & & & & & \\
\hline$>10$ & 0.979 & $0.419-2.285$ & 0.961 & & & \\
\hline
\end{tabular}

Neutrophile granulocyte (10^9/L)

$\begin{array}{ll}\leq 7.0 & \text { REF } \\ >7.0 & 0.942\end{array}$

REF

$0.361-2.456$

0.942

Leukomonocyte (10^9/L)

$$
\leq 0.8
$$

$>0.8$

\section{REF}

0.545

Hemoglobin $(g / L)$

$\begin{array}{ll}\geq 120 & \text { REF } \\ <120 & 0.77\end{array}$

Albumin (g/L)

$\begin{array}{ll}\geq 35.0 & \text { REF } \\ <35.0 & 0.565\end{array}$

Troponin-I (ug/L)

$$
\leq 0.02
$$$$
>0.02
$$$$
\text { REF }
$$

NT-ProBNP $(\mathrm{pg} / \mathrm{mL})$

$\begin{array}{ll}\leq 349 & \text { REF } \\ >349 & 1.442\end{array}$

Serum creatinine (umol/L)

$\begin{array}{ll}\leq 135 & \text { REF } \\ >135 & \mathbf{2 . 3 6 5}\end{array}$

Lactic acid (mmol/L)
2.365

$0.982-5.696$
REF

1.965

$0.493-7.829$

0.338 
Table 4 Univariate and multivariate analyses for all patients who underwent surgery (Continued)

\begin{tabular}{|c|c|c|c|c|c|c|}
\hline \multirow[t]{2}{*}{ Variable } & \multicolumn{3}{|c|}{ Univariate Model } & \multicolumn{3}{|c|}{ Multivariate Model } \\
\hline & $\mathrm{OR}$ & $95 \% \mathrm{Cl}$ & $p$-value & $\mathrm{OR}$ & $95 \% \mathrm{Cl}$ & $p$-value \\
\hline \multicolumn{7}{|l|}{$\leq 2.5$} \\
\hline$>2.5$ & 2.287 & $0.735-7.116$ & 0.153 & & & \\
\hline \multicolumn{7}{|c|}{ Alanine aminotransferase (IU/L) } \\
\hline \multicolumn{7}{|l|}{$\leq 40$} \\
\hline$>40$ & 0.650 & $0.285-1.483$ & 0.306 & & & \\
\hline \multicolumn{7}{|c|}{ Aspartate aminotransferase (IU/L) } \\
\hline \multicolumn{7}{|l|}{$\leq 46$} \\
\hline$>46$ & 0.605 & $0.258-1.415$ & 0.246 & & & \\
\hline
\end{tabular}

$\mathrm{EF}(\%)$

$\begin{array}{llll}\geq 60.0 & \text { REF } & & \\ <60.0 & 1.128 & 0.431-2.954 & 0.807\end{array}$

Marfan Syndrome

no $\quad$ REF

$\begin{array}{llll}\text { yes } & 1.275 & 0.236-6.891 & 0.778\end{array}$

Hypertension

$\begin{array}{llll}\text { no } & \text { REF } & & \\ \text { yes } & 2.469 & 0.505-12.080 & 0.265\end{array}$

Diabetes

\begin{tabular}{|c|c|c|c|}
\hline no & REF & & \\
\hline yes & 0.33 & $0.040-2.703$ & 0.302 \\
\hline
\end{tabular}

Pericardial effusion (Medium or above)

$\begin{array}{ll}\text { no } & \text { REF } \\ \text { yes } & 3.281\end{array}$

$0.444-24.234$

0.244

MPS

$\begin{array}{ll}\text { no } & \text { REF } \\ \text { yes } & 1.877\end{array}$

$0.583-6.043$

0.291

AR (Medium or above)

$\begin{array}{lll}\text { no } & \text { REF } & \\ \text { yes } & 0.731 & 0.287-1.866\end{array}$

History of cardiac surgery

$\begin{array}{ll}\text { no } & \text { REF } \\ \text { yes } & 1.65\end{array}$

1.65

$0.464-5.863$

0.439

Operative time ( $\mathrm{min})$

$\leq 306$

$>306$

REF

1.962

$0.899-4.279$

0.09

REF

3.635

$0.977-13.521$

0.054

CPB time (min)

$\begin{array}{ll}\leq 149 & \text { REF } \\ >149 & 0.894\end{array}$

Aortic Clamp time (min) 
Table 4 Univariate and multivariate analyses for all patients who underwent surgery (Continued)

\begin{tabular}{|c|c|c|c|c|c|c|}
\hline \multirow[t]{2}{*}{ Variable } & \multicolumn{3}{|c|}{ Univariate Model } & \multicolumn{3}{|c|}{ Multivariate Model } \\
\hline & $\overline{\mathrm{OR}}$ & $95 \% \mathrm{Cl}$ & $\overline{p \text {-value }}$ & $\overline{\mathrm{OR}}$ & $95 \% \mathrm{Cl}$ & $\overline{p \text {-value }}$ \\
\hline$\leq 51$ & REF & & & & & \\
\hline$>51$ & 1.324 & $0.601-2.920$ & 0.486 & & & \\
\hline \multicolumn{7}{|c|}{ SBP time (min) } \\
\hline$\leq 9.7$ & REF & & & & & \\
\hline$>9.7$ & 1.037 & $0.468-2.296$ & 0.929 & & & \\
\hline \multicolumn{7}{|c|}{ CA time (min) } \\
\hline$\leq 3.1$ & REF & & & & & \\
\hline$>3.1$ & 1.121 & $0.489-2.568$ & 0.787 & & & \\
\hline \multicolumn{7}{|c|}{ Aortic Root Concomitant procedure } \\
\hline no & REF & & & & & \\
\hline yes & 0.659 & $0.294-1.478$ & 0.312 & & & \\
\hline
\end{tabular}

blood within $10 \mathrm{~min}$ after the onset of disease. Various studies have confirmed the potential sensitivity and specificity of d-dimer, which is valuable in early diagnosis, differential diagnosis, and prognosis prediction [4, 5, 20-22]. However, few studies examined if D-dimer can provide a valuable clinical prediction for early complications after ATAAD, and evidence is needed to assess the combination of indicators for predicting risk. This study showed that preoperative IL-6 and D-dimer appear to predict early poor postoperative prognosis after ATAAD, and they have great prospective application in preoperative biochemical joint assessment. They can be very good for predicting poor early postoperative prognosis and have advantages of being rapid, non-invasive and easy to operate [23].

Preoperative concentrations of IL-6 and D-dimer in patients with ATAAD were measured, and it was found that there was statistical significance in indicators between the two groups A and B, which had clinical value in predicting early poor postoperative prognosis. IL-6 levels in groups A and group B was $57.8 \pm 39.0$ and $211.0 \pm 153.7 \mathrm{pg} / \mathrm{mL}(p<0.001)$, respectively, and corresponding D-dimer levels were $7.3 \pm 6.1$ and $16.7 \pm 5.8$ $\mu \mathrm{g} / \mathrm{mL}(p<0.001)$. ROC curve analysis showed that the truncation value of IL-6 was $108 \mathrm{pg} / \mathrm{mL}$ and that of Ddimer was $14.0 \mu \mathrm{g} / \mathrm{mL}$. Single factor and multi-factor analysis revealed the ORs of plasma IL-6 $>108 \mathrm{pg} / \mathrm{mL}$ and D-dimer > $14.0 \mu \mathrm{g} / \mathrm{mL}$ (24.937 (6.837, 90.931); $18.757(5.094,69.075)$ was a risk factor for poor

Table 5 Diagnostic value of IL-6 and D-dimer for poor postoperative prognosis

\begin{tabular}{lccll}
\hline & AUC & Cut-off value & $95 \% \mathrm{Cl}$ & $\boldsymbol{P}$ value \\
\hline IL-6 (pg/mL) & 0.901 & 108.0 & 0.839 to 0.963 & $<0.001$ \\
D-dimer (ug/mL) & 0.817 & 14.0 & 0.731 to 0.903 & $<0.001$ \\
IL-6 + D-dimer & 0.936 & & 0.793 to 0.979 & $<0.001$ \\
\hline
\end{tabular}

postoperative prognosis after ATAAD. This result is helpful for more accurate and precise consultations with patients and families before surgery, so that the family of the patient can fully understand the critical condition of the patient effectively; it is good for reducing some medical disputes.

Most clinical symptoms in patients with ATAAD include sudden chest back pain, but, due to anatomical factors, a portion of patients show paroxysmal abdominal pain, waist pain, headache, dizziness, vomiting, hemiplegia, both lower limbs weakness, and hematochezia. These not only increase the difficulty of diagnosis, but also make it easy to misdiagnose and not diagnose $[4,24,25]$. ROC curve analysis also showed that the cut-off value of IL-6 was $108 \mathrm{pg} / \mathrm{mL}$, the cut-off value of D-dimer was $14.0 \mu \mathrm{g} /$ $\mathrm{mL}$, and the AUC of IL- 6 and D-dimer were 0.905 and 0.817 , respectively. When IL- 6 and D-dimer were used in combination, the AUC reached 0.936 . The sensitivity and specificity of IL- $6>108 \mathrm{pg} / \mathrm{mL}$ for early adverse prognosis after acute aortic dissection were 91.2 and $89.7 \%$, respectively (95\% CI 0.839 to 0.963$)$. The sensitivity and specificity of D-dimer $>14.0 \mu \mathrm{g} / \mathrm{mL}$ were 88.2 and $82.2 \%$, respectively (95\% CI 0.731 to 0.903 ). (Table 4 and Fig. 3 ). In summary, IL-6 $>108 \mathrm{pg} / \mathrm{mL}$ and D-dimer $>14.0 \mu \mathrm{g} / \mathrm{mL}$ is of high predictive value for the assessment of early poor postoperative prognosis after ATAAD. And IL- $6>108 \mathrm{pg} /$ $\mathrm{mL}$ in combination with D-dimer $>14.0 \mu \mathrm{g} / \mathrm{mL}$ is of higher predictive value.

In addition, eight patients died in research group B, with a mortality rate of $5.67 \%$. Single organ/multiple organ dysfunction included 28 cases (19.9\%), while some patients have been accompanied by complications before operated such as poor perfusion syndrome (11.8\%). However, our research shows that variation between patients with preoperative complications and intraoperative data of poor postoperative prognosis had no statistical significance (Tables 2 and 3). This is related to the improvement and technical level of our 
center in the surgical treatment of ATAAD. Relevant surgical procedures have been noted in the literature [13, 26]. However, we believe that future prospective cohort studies on preoperative assessment system of patients may help us in our hospital with the assessment for high-risk patients, we can be certain about decisions for perioperative interventional therapy. We can also perform the ascending aorta replacement + hemiarch replacement, give up total arch replacement, and include a self-adaptive triple-branched stent graft implantation. When the surgical operation time is short, there will be no need to be under deep low temperature circulatory arrest. It can save the patient's life, this is also our plan in the future, creating more opportunities to help patients with wider range of replacement of aortic dissection, reduce the incidence of serious postoperative complications, and postoperative mortality.

\section{Limitations}

In this study, a small sample was retrospectively analyzed, and its outcome could limit the statistics, but still has relevant statistical value. We hope to continue the preoperative IL-6/D-dimer combination for further research, including an increased sample size and more joint biochemical indexes to provide us with more accurate prediction of poor prognosis after ATAAD.

\section{Conclusions}

IL-6 $>108 \mathrm{pg} / \mathrm{mL}$ and D-dimer $>14.0 \mu \mathrm{g} / \mathrm{mL}$ have high predictive value for the assessment of early poor postoperative prognosis after ATAAD. Moreover, IL-6 $>108$ $\mathrm{pg} / \mathrm{mL}$ in combination with D-dimer $>14.0 \mu \mathrm{g} / \mathrm{mL}$ is of higher predictive value.

\section{Abbreviations \\ ATAAD: Acute Stanford type A Aortic Dissection; IL-6: Interleukin-6; ROC: Receiver Operating Characteristic; ORs: Odds Ratios; AUC: Area under the curve; CTA: Computed Tomography angiography; MRA: Magnetic resonance angiography; CABG: Coronary Artery Bypass Grafting; AVR: Aortic valve placement; MODS: Multiorgan dysfunction; MPS: Malperfusion syndrome; CNS: Central nervous system; IC: Intermediate care; ICU: Intensive care unit; BMI: Body mass index; PT: Prothrombin time; EF: Left ventricular ejection fraction; NT-ProBNP: N-termininal forebrain natriuretic peptide; AR: Aortic regurgitation; CPB: Cardiopulmonary bypass time; SBP: Selective cerebral perfusion; CA: Circulatory Arrest}

\section{Acknowledgements}

Not applicable

\author{
Authors' contributions \\ Liangwan Chen designed the study and submitted the manuscript. \\ Qingsong Wu and Jiahui Li prepared the first draft of the manuscript and \\ made the literature review. Liangliang Yan and Zhihuang Qiu made \\ substantial changes in the manuscript together. Yue Shen,Xianbiao Xie and \\ Linfeng Xie collected and analyzed data together. All authors read and \\ approved the final manuscript.
}

\section{Funding}

Funded by the Fujian Province Fiscal Special Funds (2016XH002) and the Fujian Province Major Science and Technology Program (2018YZ001-1).
Availability of data and materials

Please contact author for data requests.

Ethics approval and consent to participate

This study was approved by the ethics committee of our hospital and conformed to the Declaration of Helsinki.

\section{Consent for publication}

Not applicable.

\section{Competing interests}

The authors declared no potential conflicts of interest with respect to the research, authorship, and/or publication of this article.

\section{Author details}

${ }^{1}$ Department of Cardiac Surgery, Union Hospital, Fujian Medical University, Fuzhou, Fujian 350001, People's Republic of China. 'Fujian Medical University, Fuzhou, Fujian 350001, People's Republic of China.

Received: 18 March 2020 Accepted: 23 June 2020

Published online: 16 July 2020

\section{References}

1. Nienaber CA, Clough RE. Management of acute aortic dissection. Lancet. 2015;385:800-11.

2. Rampold V, Trimarchi S, Eagle KA, Nienaber CA, Oh JK, Bossone E, et al. Simple risk models to predict surgical mortality in acute type a aortic dissection: the international registry of acute aortic dissection score. Ann Thorac Surg. 2007;83:55-61.

3. Ju X, ljaz T, Sun H, Ray S, Lejeune W, Lee C, et al. Interleukin-6-signal transducer and activator of transcription-3 signaling mediates aortic dissections induced by angiotensin II via the T-helper lymphocyte 17interleukin 17 axis in C57BL/6 mice. Arterioscler Thromb Vasc Biol. 2013;33: 1612-21.

4. Suzuki T, Distante A, Zizza A, Trimarchi S, Villani M, et al. Diagnosis of acute aortic dissection by D-dimer: the international registry of acute aortic dissection substudy on biomarkers (IRAD-bio) experience. Circulation. 2009; 119:2702-7.

5. Nazerian P, Mueller C, Soeiro AM, Leidel BA, Salvadeo S, Giachino F, et al. ADVISED investigators. Diagnostic accuracy of the aortic dissection detection risk score plus D-dimer for acute aortic syndromes: the ADVISED prospective multicenter study. Circulation. 2018;137:250-8.

6. Itagaki R, Kimura N, Mieno M, Hori D, Itoh S, et al. Characteristics and treatment outcomes of acute type A aortic dissection with elevated Ddimer concentration. J Am Heart Assoc. 2018;7:e009144.

7. Brocca A, Virzi GM, de Cal M, Giavarina D, Carta M, Roncon C. Elevated levels of procalcitonin and interleukin-6 are linked with postoperative complications in cardiac surgery. Scand J Surg. 2017:106:318-24.

8. Wen M, Han Y, Ye J, Cai G, Zeng W, Liu X, et al. Peri-operative risk factors for in-hospital mortality in acute type A aortic dissection. J Thorac Dis. 2001;11: 3887-95.

9. Dindo D, Demartines N, Clavien PA. Classification of surgical complications: a new proposal with evaluation in a cohort of 6336 patients and results of a survey. Ann Surg. 2004;240:205-13.

10. Gourd NM, Nikitas N. Multiple organ dysfunction syndrome. J Intensive Care Med. 2019;885066619871452.

11. Chiu P, Tsou S, Goldstone AB, Louie M, Woo YJ, Fischbein MP. Immediate operation for acute type $A$ aortic dissection complicated by visceral or peripheral malperfusion. J Thorac Cardiovasc Surg. 2018;156:18-24.e3.

12. Ghoreishi M, Wise ES, Croal-Aprahams L, Tran D, Pasrija C, Drucker CB, et al. A novel risk score predicts operative mortality after acute type a aortic dissection repair. Ann Thorac Surg. 2018;106:1759-66.

13. Chen LW, Dai XF, Wu XJ, Liao DS, Hu YN, Zhang H, et al. Ascending aorta and hemiarch replacement combined with modified triple-branched stent graft implantation for repair of acute Debakey type I aortic dissection. Ann Thorac Surg. 2017;103:595-601.

14. Chen LW, Wu XJ, Dai XF, Liao DS, Li C, Wang QM, et al. A self-adaptive triple-branched stent graft for arch repair during open type A dissection surgery. J Thorac Cardiovasc Surg. 2015;149:1278-83.e1.

15. Avouac J, Meune C, Chenevier-Gobeaux C, Dieude P, Borderie D, Lefevre G, et al. Inflammation and disease activity are associated with high circulating 
cardiac markers in rheumatoid arthritis independently of traditional cardiovascular risk factors. J Rheumatol. 2014:41:248-55.

16. Hiratzka LF, Bakris GL, Beckman JA, Bersin RM, Carr VF, Casey DE, et al. 2010 ACCF/AHA/AATS/ACR/ASA/SCA/SCAI/SIR/STS/SVM guidelines for the diagnosis and management of patients with thoracic aortic disease. A report of the American College of Cardiology Foundation/American Heart Association Task Force on Practice Guidelines, American Association for Thoracic Surgery, American College of Radiology, American Stroke Association, Society of Cardiovascular Anesthesiologists, Society for Cardiovascular Angiography and Interventions, Society of Interventional Radiology, Society of Thoracic Surgeons, and Society for Vascular Medicine. J Am Coll Cardiol. 2010;55:e27-e129.

17. Nagareddy P, Smyth SS. Inflammation and thrombosis in cardiovascular disease. Curr Opin Hematol. 2013;20:457-63.

18. Halefoglu AM. CT diagnosis of a thoracic aortic aneurysm with type B aortic dissection clinically misdiagnosed as acute pulmonary embolism. Case Rep Med. 2012;2012:720394. https://doi.org/10.1155/2012/720394.

19. Proietta M, Tritapepe L, Cifani N, Ferri L, Taurino M, Del Porto F. MMP-12 as a new marker of Stanford-a acute aortic dissection. Ann Med. 2014;46:44-8.

20. Eggebrecht $\mathrm{H}$, Naber $\mathrm{CK}$, Bruch $\mathrm{C}$, et al. Value of plasma fibrin D-dimers for detection of acute aortic dissection. J Am Coll Cardiol. 2004;44:804-9.

21. Weber T, Hogler S, Auer J, Berent R, Lassnig E, Kvas E, et al. D-dimer in acute aortic dissection. Chest. 2003;123:1375-8.

22. Sodeck G, Domanovits $H$, Schillinger M, Ehrlich MP, Endler G, Herkner $H$, et al. D-dimer in ruling out acute aortic dissection: a systematic review and prospective cohort study. Eur Heart J. 2007;28:3067-75.

23. Iafolla M. Rheumatoid arthritis and atypical cardiovascular disease: inflammation changing the clinical presentation. Can Fam Physician. 2013; 59:505-9.

24. Hansen MS, Nogarede GJ, Hutchison SJ. Frequency of and inappropriate treatment of misdiagnosis of acute aortic dissection. Am J Cardiol. 2007;99: 852-6.

25. Harris KM, Strauss CE, Eagle KA, Hirsch AT, Isselbacher EM, Tsai TT, et al. Correlates of delayed recognition and treatment of acute type a aortic dissection : the international registry of acute aortic dissection (IRAD). Circulation. 2011;124:1911-8.

26. Chen LW, Lu L, Dai XF, Wu XJ, Zhang GC, Yang GF, et al. Total arch repair with open triple-branched stent graft placement for acute type a aortic dissection: experience with 122 patients. J Thorac Cardiovasc Surg. 2014;148; $521-8$.

\section{Publisher's Note}

Springer Nature remains neutral with regard to jurisdictional claims in published maps and institutional affiliations.

Ready to submit your research? Choose BMC and benefit from:

- fast, convenient online submission

- thorough peer review by experienced researchers in your field

- rapid publication on acceptance

- support for research data, including large and complex data types

- gold Open Access which fosters wider collaboration and increased citations

- maximum visibility for your research: over $100 \mathrm{M}$ website views per year

At BMC, research is always in progress.

Learn more biomedcentral.com/submissions 